\title{
ENTREVISTA
}

\section{DESAFIOS DA EDUCAÇÃO A DISTÂNCIA BRASILEIRA}

regime de colaboração entre União, Estados e Municípios na coordenação da qualidade da Educação a Distância no Brasil e a evolução de sua oferta para acompanhar o mercado que cresce mundialmente ao ritmo das tecnologias da informação e comunicação são o tema desta entrevista.

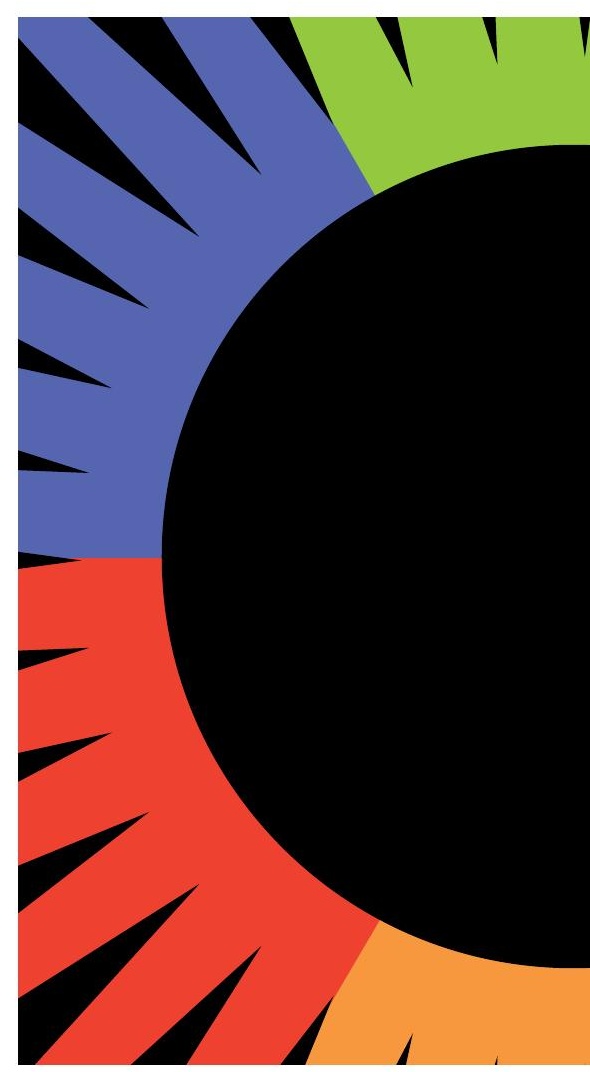




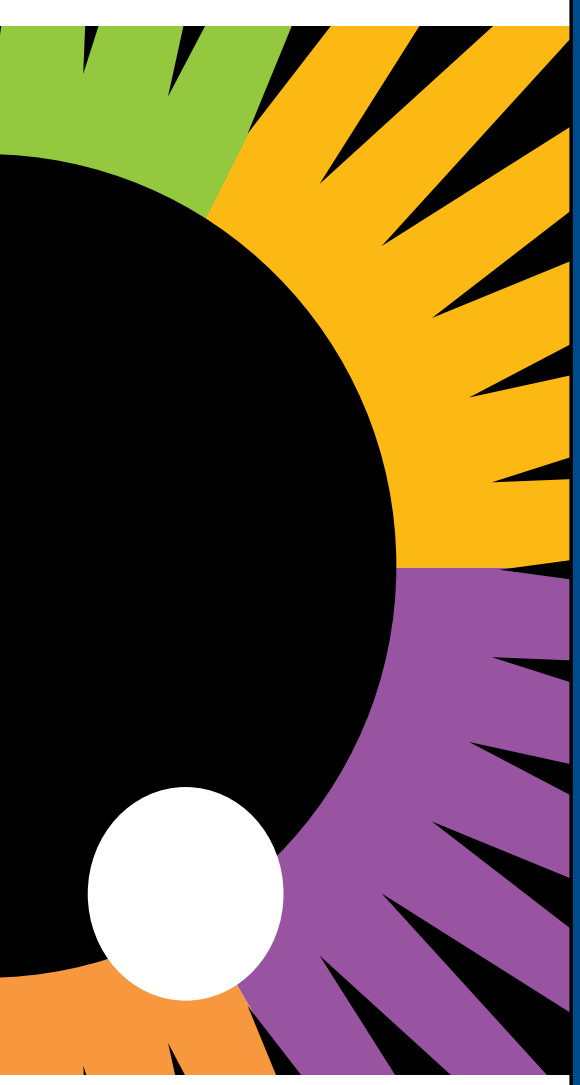

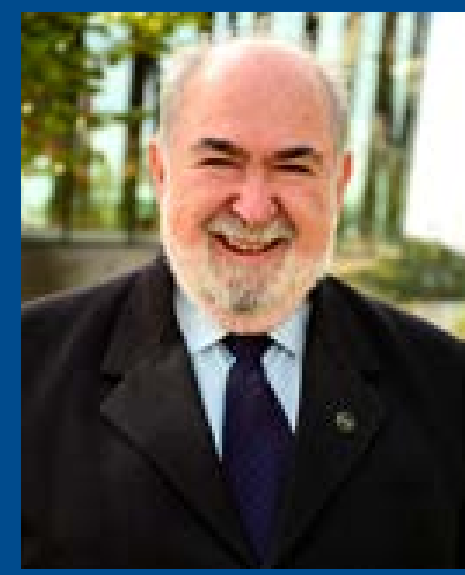

Professor Francisco Aparecido Cordão

Conselheiro da Câmara de Educação Básica do Conselho Nacional de Educação. Titular da Cadeira n. 28 da Academia Paulista de Educação. Especialista em Educação Profissional e Consultor da Peabiru Educacional.

facordao@uol.com.br

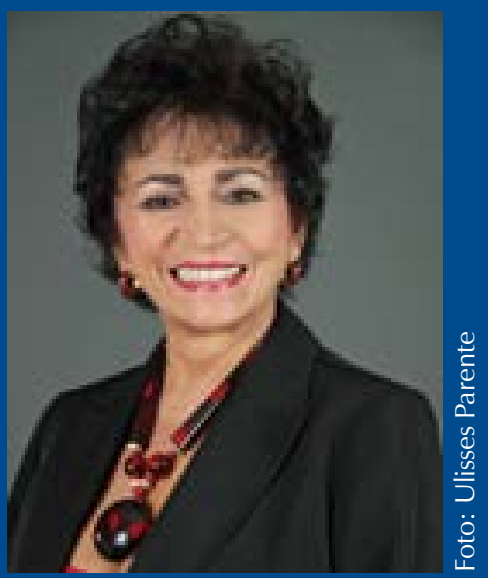

Professora Suely Melo de Castro Menezes

Presidente do Conselho Estadual de Educação do Pará e do Fórum Nacional de Conselhos Estaduais de Educação. Conselheira da Câmara de Educação Básica do CNE.

suelymcmenezes@gmail.com 
Francisco Aparecido Cordão - Desde meados do ano de 2010, a Câmara de Educação Básica (CEB) do CNE, em conjunto com o Ministério da Educação, inicialmente com a então Secretaria de Educação a Distância e em articulação com o Fórum Nacional dos Conselhos Estaduais de Educação, tem debatido propostas para um regime de colaboração entre os Sistemas de Ensino visando a oferta de programas de Educação a Distância (EAD) no âmbito da Educação Básica, em especial para a oferta de cursos de Ensino Médio e programas de Educação de Jovens e Adultos e de Educação Profissional Técnica de Nível Médio. Esse assunto havia sido debatido em uma reunião do Fórum no Maranhão, onde chegou a ser redigida uma "Carta do Maranhão" sobre o tema. Ainda no fim de 2010, em reunião plenária do Fórum Nacional dos Conselhos Estaduais de Educação, realizada em Vila Velha, no Espírito Santo, essa proposta foi tema de exaustivo debate, mas não houve consenso. O assunto foi retomado em outras reuniões do Fórum, nas diferentes regiões do Brasil, em especial no Norte e no Nordeste e considerado consenso na reunião plenária geral do Fórum Nacional dos ConseIhos Estaduais de Educação, no fim de 2011, na cidade do Rio de Janeiro. Finalmente, em 10 de maio de 2012, a CEB aprovou, por unanimidade, o Parecer CNE/CEB n. 12/2012, que definia Diretrizes Operacionais Nacionais para a oferta de Educação a Distância (EAD), em regime de colaboração entre os sistemas de Ensino, no âmbito da Educação Básica. Esse Parecer, entretanto, após longa tramitação nos diversos órgãos técnicos do MEC, não foi homologado. Enquanto isso, o mesmo acabou sendo objeto de diversos questionamentos por parte de alguns Conselhos Estaduais de Educação, bem como por diversos educadores e estudiosos da área da Educação a Distância. Considerando a complexidade da matéria, o Conselho Nacional de Educação decidiu realizar uma pesquisa sobre o assunto, em parceria com a Organização das Nações Unidas para a Educação, a Ciência e a Cultura (Unesco). O próprio Fórum Nacional dos Conselhos Estaduais de Educação também constituiu grupo de trabalho especial para estudar a matéria e se posicionar sobre o tema da Educação a Distância no âmbito da Educação Básica, apresentando ao Conselho Nacional de Educação um completo material analítico e propositivo, o qual foi amplamente aproveitado pelo CNE. Esses estudos apontavam para um cenário desafiador, principalmente frente ao avanço e à expansão das Tecnologias de Informação e Comunicação (TIC), geradoras de mudanças em todos os níveis e esferas da sociedade, gerando novos estilos de vida e formas de trabalho, as quais passaram a exigir novas maneiras de ensinar e de aprender. Nesse sentido, a Educação a Distância apresenta-se como uma possibilidade, por excelência, da consecução do direito inalienável do cidadão à educação, independentemente dos limites físicos, temporais e territoriais a que esteja circunscrita. Nesse contexto, o Fórum de Conselhos Estaduais de Educação 


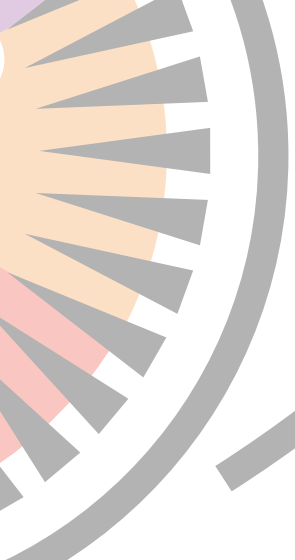

bate em uma Reunião Plenária do Fórum Ampliado de Conselhos de Educação, realizada na sede do Conselho Nacional de Educação. Todas as contribuições apresentadas foram consideradas em dois documentos normativos produzidos pelo Conselho Nacional de Educação: um no âmbito da Câmara de Educação Superior, que resultou na aprovação do Parecer CNE/CES n. 564/2015 e deu origem à Resolução CNE/CES n. 01/2016, e outro no âmbito da CEB, que resultou na aprovação do Parecer CNE/CEB n. 2/2015, em 11 de março de 2015 que, ao ser encaminhado ao Gabinete do Ministro da Educação para a devida homologação, foi objeto de intensa movimentação nos órgãos próprios do MEC e de atenta análise por parte da Consultoria Jurídica (Conjur) do MEC, que apresentou Parecer favorável à aprovação e devida homologação ministerial, apenas após algumas alterações propostas no Projeto de Resolução anexo ao Parecer CNE/CEB n. 2/2015, em especial para atendimento às normas definidas pela Lei n. 12.513/2011, que instituiu o Programa Nacional de Acesso ao Ensino Técnico e Emprego (Pronatec), principalmente com a redação dada pela Lei n. 12.816/2015. Essas considerações da Conjur/MEC foram apresentadas ao CNE pela Secretaria de Educação Profissional e Tecnológica (Setec/MEC). Em 11 de novembro de 2015, a CEB, após amplo debate interno, inclusive com participação de representantes do MEC e do próprio Fórum Nacional de Conselhos Estaduais de Educação, aprovou o Parecer CNE/CEB n. 13/2015, o qual, uma vez devidamente homologado pelo MEC, em 28 de janeiro de 2016, deu origem à Resolução CNE/CEB n. 01/2016.

A senhora, mais do que ninguém, participou ativamente de toda essa movimentação, desde a "Carta do Maranhão" até a publicação da resolução CNE/CEB n. 01/2016. A senhora julga que esse demorado processo de debates para a aprovação do novo marco legal da EAD no Brasil provocou avanços significativos na oferta ou simplesmente retardou o processo, uma vez que os reais problemas ainda continuam sem solução? Qual é o seu posicionamento, como Presidente do Fórum Nacional de Conselhos 
Estaduais de Educação e, agora, como nova Conselheira da Câmara de Educação Básica do Conselho Nacional de Educação, sobre a realidade da Educação a Distância no Brasil? Essa decisão de operacionalizar sua oferta, realizando sua supervisão em regime de colaboração entre os Sistemas de Ensino é uma decisão acertada? A senhora aposta na eficiência e eficácia desse Regime de Colaboração para garantir uma Educação a Distância Democrática e de Qualidade em todos os níveis de Educação e Ensino neste Brasil de dimensões continentais?

Suely Melo de Castro Menezes - Quando penso nessa longa trajetória da discussão da EAD em Regime de Colaboração entre os Sistemas de Ensino, tenho certeza de que a mudança e a renovação de conceitos das pessoas são muito mais rápidas do que acontece em instituições normativas, como são os Conselhos de Educação. As pessoas que dirigem essas instituições apresentam propostas inovadoras, renovam, reinventam suas ideias, colocando-as em debate nas instituições onde geram embates, discordâncias e demoradas discussões.

Ao longo dos últimos 15 anos, a EAD e o Regime de Colaboração ocuparam denso espaço de debates nos diferentes fóruns de educação deste país, no âmago das próprias instituições públicas e privadas na área educacional.

Em um país tão grande e diverso com o nosso, é até compreensível a variação de conceitos, muito entrelaçada pelo olhar ou pelo ângulo por meio do qual se enxerga a realidade e suas circunstâncias. Quando se discutiu EAD, nesta última década, sempre o país dividiu opiniões.

A parte do país que se movimenta bem por estradas e que é enriquecida pela grande quantidade e boa qualidade de ofertas educacionais, muitas vezes adiou o debate das propostas, questionou seus fundamentos e princípios, até mesmo atrapalhou o avanço dos programas e da regulamentação da EAD, sob o álibi da eventual pouca qualidade dessa modalidade de ensino e educação e até mesmo da pouca fidedignidade metodológica ou ainda da pouca seriedade de muitas das propostas apresentadas.

A outra parte do país, que poderíamos denominar como o mundo das águas, que não consegue ofertar além de $20 \%$ da educação de nível superior e que não ultrapassa os 3\% de acesso aos programas de mestrado e de doutorado, olha a EAD como uma virtual solução para quebrar essa muralha de desigualdades que impede o avanço educacional da região, como se ainda vivêssemos em vários Brasís, ainda divididos por um Tratado de Tordesilhas. 
caz de modernas tecnologias e de metodologias facilitadoras da obtenção de melhores resultados de aprendizagem. Foi também um tempo propício de rompimento dos muros, de ampliação das fronteiras dos saberes, de modernização dos espaços de ensino e aprendizagem, da gestão dos territórios, exigindo um olhar para além dos limites estabelecidos, gerando uma real possibilidade de construção conjunta de uma proposta possível de ser implantada em regime de colaboração.

Francisco Aparecido Cordão - O Art. 211 da Constituição Federal define que "a União, os Estados, o Distrito Federal e os Municípios organizarão em regime de colaboração seus sistemas de ensino". O § 4을 do mesmo artigo determina que "na organização de seus Sistemas de Ensino, a União, os Estados, o Distrito Federal e os Municípios definirão formas de colaboração, de modo a assegurar a universalização do Ensino Obrigatório". Já o Parágrafo Único do Art. 22 da Constituição Federal, na redação dada pela Emenda Constitucional n. 53/2006, prevê que "Leis Complementares fixarão normas para a cooperação entre a União e os Estados, o Distrito Federal e os Municípios, tendo em vista o equilíbrio do desenvolvimento e do bem-estar em âmbito nacional". A senhora não considera que a Resolução CNE/CEB n. 01/2016 já se adiantou a essa Lei Complementar, que poderá ter muita dificuldade em sua tramitação até a aprovação por parte do Congresso Nacional, definindo normas operacionais que facilitarão a efetiva implantação do regime de colaboração entre os Sistemas de Ensino para garantir uma efetiva Educação a Distância Democrática e de Qualidade no Brasil?

Suely Melo de Castro Menezes - Na verdade, a dimensão continental do Brasil tem dificultado grandemente a supervisão e o controle da EAD, tanto no nível da Educação Básica quanto na Educação Superior. Especificamente em relação ao nível superior, mesmo com o MEC envidando grande esforço nessa direção, poder-se-ia pensar em uma alternativa de supervisão articulada pelo regime de colaboração entre os diversos sistemas de ensino, envolvendo os Estados nessa empreitada.

Essa realidade representa um sólido indicativo de que a oferta e supervisão em regime de colaboração entre os sistemas de ensino pode ser a solução estratégica, que pela maior capilaridade multiplica o acompanhamento e a avaliação dos programas que atravessam as fronteiras dos estados, dos municípios e das instituições, principalmente quando falamos de educação básica e profissional, com seus números surpreendentes e proliferação acelerada.

Vale ressaltar também que a implantação de uma política de efetiva colaboração entre os diferentes sistemas de ensino promove a comunicação e articulação entre o sistema de origem e o sistema receptor da instituição 
ofertante, desenvolvendo uma proposta de rede entre as instituições educacionais e os diversos Conselhos de Educação e respectivos sistemas.

Francisco Aparecido Cordão - Na qualidade de Presidente do Fórum Nacional de Conselhos Estaduais de Educação, com longa experiência na direção do Conselho Estadual de Educação do Pará e, agora, como nova Conselheira da Câmara de Educação Básica do Conselho Nacional de Educação, quais são os principais desafios que a senhora vislumbra, que deverão ser enfrentados para a efetiva implantação dessas Diretrizes Operacionais definidas pelo Conselho Nacional de Educação, em regime de colaboração entre os Sistemas de Ensino do Brasil?

Suely Melo de Castro Menezes - Não tenho dúvida de que o Regime de Colaboração, devidamente disciplinado e normatizado adequadamente, pode trazer muitos e significativos benefícios e avanços, principalmente em termos de troca de experiências educacionais, na avaliação institucional compartilhada, na supervisão da qualidade de oferta e até mesmo no acompanhamento dos resultados dos egressos.

O conjunto desses fatores somados potencializam as efetivas condições de eficiência e eficácia na oferta de uma educação de qualidade, fundamentada pelos resultados positivos alcançados e pela democratização do acesso do alunado trabalhador ou morador em áreas remotas às efetivas oportunidades educacionais, as quais têm nos programas de EAD a grande solução para mudança de vida pela real democratização das oportunidades educacionais de qualidade.

Francisco Aparecido Cordão - O que mais gostaria de apontar como relevante sobre essa matéria para os leitores do Boletim Técnico do Senac - a Revista da Educação Profissional? A Resolução CNE/CEB n. 01/2016 se adiantou na definição de Normas Operacionais que facilitarão a efetiva implantação do Regime de Colaboração entre os Sistemas de Ensino?

Suely Melo de Castro Menezes - A Resolução CNE/CEB n. 01/2016 nos permite comemorar sua aprovação como sendo uma feliz oportunidade da quebra de um paradigma que emperrou o país por muito tempo e nos colocou em uma posição de retaguarda, enquanto poderíamos muito bem estar ocupando posições de vanguarda no cenário internacional, com a transposição das fronteiras, sem o excesso de exigências burocráticas desnecessárias, simplesmente contando com a adoção do rito de confiança a ser exercitado pelos diferentes Conselhos de Educação e sistemas deste país.

A Resolução CNE/CEB, sem dúvida alguma, apresenta-se à comunidade educacional e à sociedade brasileira como um marco legal efetivo, na co- 
brança e na sistematização do Regime de Colaboração, que deve ser exercitado com vigor e empenho pelos Conselhos Estaduais e Distrital de Educação, eventualmente contando, ainda, com a colaboração dos Conselhos Municipais de Educação, na convicção de que representa nossa melhor possibilidade de gestão de processo, que se não for articulada entre os Conselhos, tende a fugir de qualquer controle.

Sempre que estamos diante de um novo conjunto de Diretrizes Nacionais a serem implantadas, deparamo-nos com as grandes diferenças entre os diferentes sistemas de ensino deste grande e diverso país chamado Brasil. Não há como contestar que temos Conselhos bem aparelhados, com autonomia financeira e deliberativa, com políticas de gestão modernas e participativas. Temos também aqueles Conselhos que ainda estão atrelados à boa vontade do Executivo, sem mobilidade, sem autonomia, sem aparato tecnológico, sem prestigio político. Essas diferenças verificadas em muitas variações tendem a comprometer a plena confiança entre os diferentes Conselhos e seus respectivos Sistemas de Ensino. Sabemos, entretanto, que este é um componente fundamental para sustentar efetivamente o regime de Colaboração entre os diferentes Sistemas de Ensino, em todas as instâncias federativas.

A dinâmica colaborativa se sustenta na confiança, na seriedade, na qualidade e na consistência dos credenciamentos concedidos às instituições, os quais devem ser acreditados pelos sistemas de ensino parceiros e seus respectivos Conselhos de Educação.
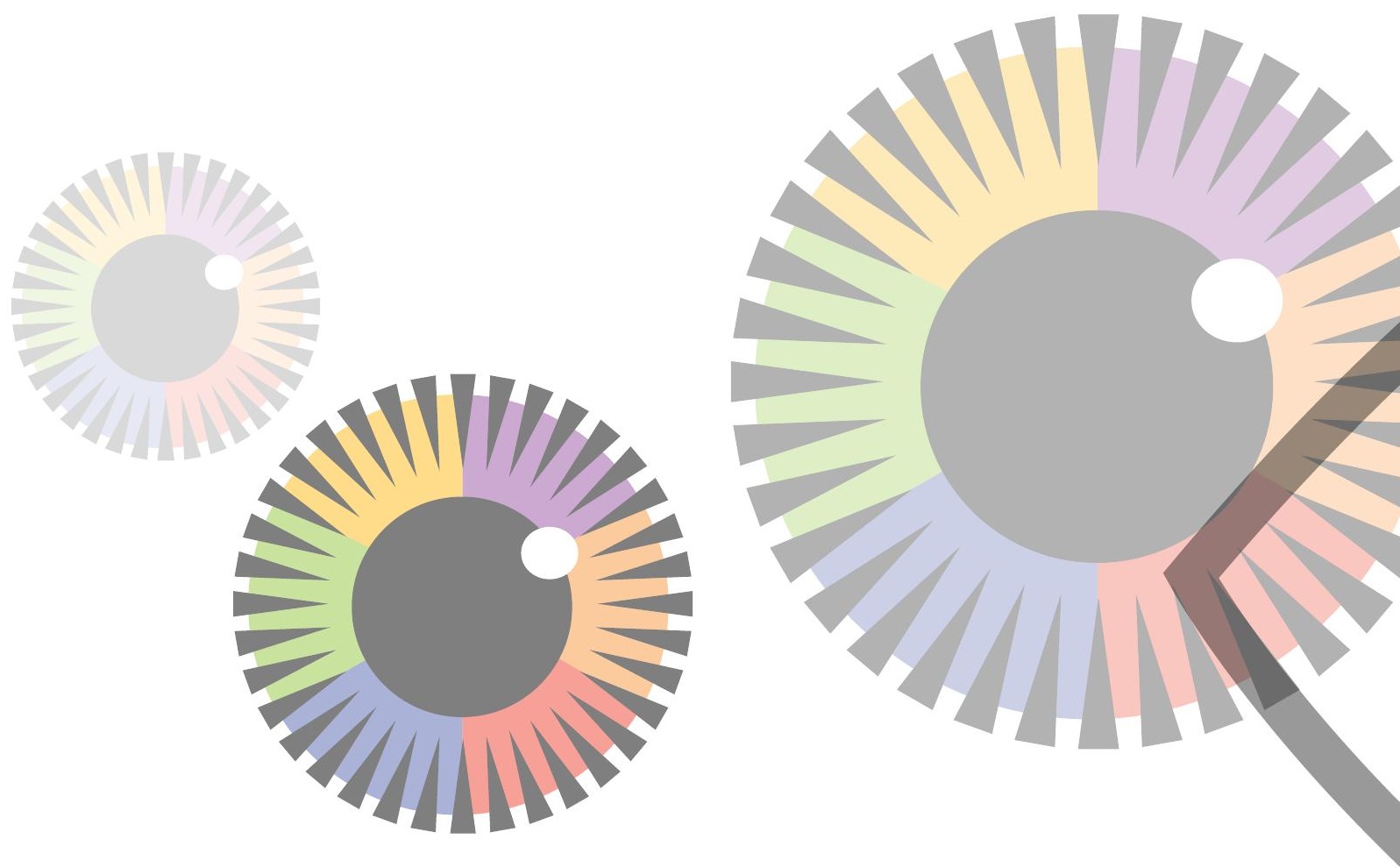

B. Téc. Senac, Rio de Janeiro, v. 42, n. 2, p. 136-145, maio/ago. 2016. 
Francisco Aparecido Cordão - Quais os principais desafios que devem ser enfrentados para efetiva implantação dessas diretrizes definidas pelo Conselho Nacional de Educação?

Suely Melo de Castro Menezes - O grande desafio, do meu ponto de vista, está no exercício da busca de consensos, da construção de protocolos dos processos, de normas conjuntas, geradoras de confiança, de acreditação nas decisões dos conselhos de educação no regime de colaboração. Esse desafio impõe como palavra de ordem a nossa meta para este semestre rumo à efetiva concretização das necessárias articulações entre os sistemas de ensino, objetivando a real consolidação da Resolução CNE/ CEB n. 01/2016.

A divisão de responsabilidades entre os nossos sistemas de ensino dos Estados e do Distrito Federal, contando também com a eventual colaboração dos Municípios no funcionamento da EAD em regime de colaboração intersistemas, deve ser olhada e preparada como um bom casamento em regime de comunhão parcial de bens. Se todo cuidado é pouco na construção dos acordos que assegurem o sucesso das parcerias e do Regime de Colaboração, por outro lado, é preciso alimentar a certeza de que todo esforço vale a pena, como já disse o poeta e ensaísta português Fernando Pessoa: "quando a alma não é pequena". 